\title{
The Impact of COVID-19 on Family Building Among Physicians and Trainees
}

J Gen Intern Med 37(6):1582-4

DOI: $10.1007 / \mathrm{s} 11606-022-07442-3$

(C) The Author(s), under exclusive licence to Society of General Internal Medicine 2022

\section{INTRODUCTION}

During the COVID-19 pandemic, fertility care in the USA was put on hold temporarily to minimize transmission of infections. ${ }^{1}$ Prior to the pandemic, physicians were more likely than non-physicians to experience fertility challenges. ${ }^{2}$ The impact of the pandemic on family building among physicians is unknown. As part of a larger study on fertility, we examined family building challenges posed by the pandemic for physicians and trainees.

\section{METHODS}

A cross-sectional study design was used to administer a fertility questionnaire between April and May 2021 to physicians and physicians-in-training. A non-probabilistic sample of participants was recruited using an infographic advertisement leveraging social media (Twitter, Instagram, Facebook, and LinkedIn networks of the authors and AMWA (American Medical Women's Association) including Facebook groups (e.g., Physician Moms Group, Gay Men Physicians Group)). Survey participants provided socio-demographic and workrelated characteristics. Using an open-ended question, survey participants were asked, "How has COVID-19 affected your family planning?" An inductive thematic analysis was conducted. $^{3}$ A group of three independent coders developed the codebook by coding responses until thematic saturation was reached $(n=200)$, two coded all responses, and differences were resolved by discussion. Quantitative analyses were conducted using SPSS Version 25 (IBM Corp). The study was approved by the University of Miami IRB.

\section{RESULTS}

Out of 3116 (90.6\% women, $n=2824)$ survey participants, 1885 responses physicians and trainees $(60.5 \%$; see Table 1$)$ responded to the free-response item about how COVID-19

Received September 23, 2021

Accepted January 28, 2022

Published online February 23, 2022 affected their family planning. Of these participants, $37.3 \%$ ( $n$ $=703$ ) said their family planning was impacted by COVID- 19 .

Our analysis identified seven major themes: delay, mental health, pregnancy experience, childcare, partnership, social support and isolation, and benefits (Table 2). Reasons stated for the most prominent theme, delaying family building, included fertility treatment challenges, inability to see their partner, delays in weddings, deliberate pauses in childbearing, COVID-19 vaccination, adoption delays, financial stressors, and change in desire to have children. Fertility treatment access challenges included scheduling appointments, fear of COVID-19 exposure, and lack of work coverage. Describing access to in vitro fertilization, one participant said: "I had a lot of frustration as someone who was putting themselves on the line every day to help people during a pandemic and who was then denied access to my own care."

Participants voiced mental health concerns associated with adding a child to their family or being pregnant during the pandemic (i.e., COVID-19 exposure, isolation, and miscarriages). Pregnancy-related difficulties included fear and anxiety related to miscarriages, absence of support at appointments and delivery, and getting COVID-19 while pregnant. Participants had difficulties obtaining childcare and/or provided childcare themselves while working from home which was stressful and prohibitive for having additional children during the pandemic.

While most comments were made by women (91.6\%), our themes did not vary across gender identities, nor did they vary by race or ethnicity.

\section{DISCUSSION}

It is critical to address the impact of the COVID-19 pandemic on the well-being of physicians, including the ability to build a family. In this first large-scale survey of physicians and trainees, the family planning of almost one-quarter of all respondents to the survey (and over one-third of those responding to the item analyzed here) was impacted by COVID-19. This finding is consistent with a national survey of the general population which showed many delayed milestones such as parenthood and marriage due to the pandemic. ${ }^{4}$ While our study is limited due to gender imbalance among participants and potential sampling bias that may slightly overestimate the impact of the pandemic, the data remain informative. 
Table 1 Socio-demographic and Work-Related Characteristics Among Survey Participants Who Answered the Question, "How Has COVID-19 Affected Your Family Planning?"

\begin{tabular}{|c|c|}
\hline Characteristic & $n(\%)^{*}$ \\
\hline \multicolumn{2}{|l|}{ Gender $^{\dagger}$} \\
\hline Woman & $1729(91.7)$ \\
\hline Man & $140(7.4)$ \\
\hline Nonbinary & $9(0.5)$ \\
\hline Agender & $1(0.1)$ \\
\hline Genderfluid & $1(0.1)$ \\
\hline Genderqueer & $4(0.2)$ \\
\hline Prefer to describe & $1(0.1)$ \\
\hline \multicolumn{2}{|l|}{$\operatorname{Sex}^{+}$} \\
\hline Female & $1741(92.4)$ \\
\hline Male & $142(7.5)$ \\
\hline Prefer to describe & $1(0.1)$ \\
\hline Prefer not to answer & $1(0.1)$ \\
\hline \multicolumn{2}{|l|}{ Age } \\
\hline Years $( \pm$ SD) & $37.1( \pm 8.8)$ \\
\hline \multicolumn{2}{|l|}{ Title } \\
\hline Medical student & $356(18.9)$ \\
\hline Resident & $234(12.4)$ \\
\hline Fellow & $132(7.0)$ \\
\hline Independent practitioner & $1143(60.6)$ \\
\hline Prefer to describe & $18(1.0)$ \\
\hline Prefer not to answer & $2(0.1)$ \\
\hline \multicolumn{2}{|l|}{ Location } \\
\hline USA & $1748(92.7)$ \\
\hline International & $124(6.6)$ \\
\hline \multicolumn{2}{|l|}{ Relationship status } \\
\hline Single & $228(12.1)$ \\
\hline Widowed & $4(0.2)$ \\
\hline Divorced & $35(1.9)$ \\
\hline Separated & $9(0.5)$ \\
\hline Married & $1344(71.3)$ \\
\hline Significant other & $213(11.3)$ \\
\hline Domestic partnership & $44(2.3)$ \\
\hline Polyamorous & $5(0.3)$ \\
\hline Prefer to describe & $1(0.1)$ \\
\hline \multicolumn{2}{|l|}{ Have children } \\
\hline Yes & $1054(55.9)$ \\
\hline No & $831(44.1)$ \\
\hline \multicolumn{2}{|l|}{ Race/ethnicity } \\
\hline Asian & $261(13.9)$ \\
\hline American Indian or Alaskan Native & $2(0.1)$ \\
\hline Black or African American & $151(8.0)$ \\
\hline Hispanic, Latinx, or Spanish origin & $21(1.1)$ \\
\hline Middle Eastern or North African & $49(2.6)$ \\
\hline Multiracial $^{\S}$ & $127(6.7)$ \\
\hline White & $1235(65.5)$ \\
\hline Prefer to describe & $22(1.2)$ \\
\hline \multicolumn{2}{|l|}{ COVID impacted family planning" } \\
\hline Medical student & $118(33.1)$ \\
\hline Resident & $111(47.4)$ \\
\hline Fellow & $75(56.8)$ \\
\hline Independent practitioner & $394(34.5)$ \\
\hline Prefer to describe & $4(22.2)$ \\
\hline
\end{tabular}

"Total numbers may vary due to item non-response or missing.

${ }^{+}$Additional response options, which no participants in this sample selected, included Gender queer and Prefer to describe.

${ }^{*}$ Additional response options, which no participants in this sample selected, included Intersex and Prefer to describe.

${ }^{\xi}$ Participants who selected more than one option are considered multiracial for the purpose of this study.

"Percentages calculated among those who responded to the item analyzed in this manuscript, representing the proportion of each group that indicated COVID-19 had impacted their family planning
Table 2 Themes Emerging from Inductive Analysis of "How Did COVID-19 Affect Your Family Planning?" Among Participants of the Fertility Survey $(n=1885)$

\begin{tabular}{lll}
\hline \hline Theme & Code & Example quote \\
\hline Delay & Fertility treatment & "I was shut out of fertility
\end{tabular}
treatment for 3 months and then my clinic wouldn't allow me to cycle because I was seeing COVID patients so had to switch clinics."

Unable to see partner "Partner was not in state during COVID and unable to see him."

Stopped trying

Vaccine

Wedding

Adoption

Financial stress

Change in desire to have children

Unspecified

Mental health Mental health

"Delayed attempt for another child due to uncertainty."

"Waited for vaccine."

"Delayed wedding and therefore conception planning."

"Put plans to pursue adoption on hold."

"Financial insecurity made us wait a bit longer to start trying."

"COVID has made us more unsure of whether we want to have children. The world seems so dangerous and it has highlighted how little people care about each other in modern times."

"Delayed it."

"Increased stress on me and my partner making it difficult to have conversations about starting a family." "Almost wasn't able to

Pregnancy Delivered during experience pandemic

Miscarriage

Pregnant during pandemic

Trying for baby

Childcare

Childcare issues

At home more-stress of caring for children

Partnership

No partner/dating

Divorce/breakup

Social support

Isolation - at appointments
"Alme my husband present at my baby's birth. What an ordeal.'

"I had a miscarriage 4/3/ 2021. My husband got a vasectomy the same day."

"I had COVID while 6

weeks pregnant in July 2020."

"Tried to squeeze in a second baby during the mandated shutdown of most travel and social activities (and succeeded)."

"Daycare got more unreliable which made it even harder to juggle kids and work. We waited to get pregnant longer."

"Kids are home from school and I'm glad I only have 2!!"

"Not able to date much which I think has slowed my trajectory in terms of meeting someone who I could eventually marry."

"Caused a breakup in my relationship."

"My partner is not allowed to be with me for my fertility treatments including when I had a miscarriage." 
Table 2. (continued)

\begin{tabular}{|c|c|c|}
\hline Theme & Code & Example quote \\
\hline \multirow{4}{*}{ Benefit } & $\begin{array}{l}\text { Social support from } \\
\text { family }\end{array}$ & $\begin{array}{l}\text { "Limited access to family } \\
\text { support. Made making } \\
\text { decisions regarding } \\
\text { childcare for young infant } \\
\text { very very hard." }\end{array}$ \\
\hline & $\begin{array}{l}\text { Made family planning } \\
\text { easier }\end{array}$ & $\begin{array}{l}\text { "Started a family sooner } \\
\text { than planned." }\end{array}$ \\
\hline & $\begin{array}{l}\text { At home } \\
\text { more-benefit to fam- } \\
\text { ily plan }\end{array}$ & $\begin{array}{l}\text { "Having everything online } \\
\text { for school made it a lot } \\
\text { easier to be pregnant } \\
\text { during didactic years." }\end{array}$ \\
\hline & $\begin{array}{l}\text { At home } \\
\text { more-decided to } \\
\text { have a child }\end{array}$ & $\begin{array}{l}\text { "We canceled our big } \\
\text { travel plans and made a } \\
\text { baby instead." }\end{array}$ \\
\hline
\end{tabular}

It is worth emphasizing that prior to the pandemic, physicians faced a higher rate of infertility and delayed childbearing compared to the general population. ${ }^{2}$ For some, additional delay due to the pandemic could be the difference between having a child and not. Our findings suggest healthcare employers should take active measures such as encouraging fertility check-ups, providing insurance coverage for fertility treatment, and educating leaders about the importance of supporting family building financially and with flexible schedules for physicians and trainees. ${ }^{5}$ Institutions that want to reverse the negative impact of the pandemic on women physicians must be intentional about incorporating these recommendations alongside other efforts such as addressing bias and harassment, improving childcare and parental leave, and providing additional research funds for women researchers. ${ }^{6}$

Acknowledgements: The authors thank the American Medical Women's Association Physician Fertility Initiative for supporting the dissemination of this survey.

Morgan S. Levy, BS ${ }^{1,2}$

Amelia G. Kelly, $M D^{3}$

Alyssa D. Brown, $B \mathrm{~S}^{4,5}$

Alberto Caban-Martinez, $\mathrm{DO}, \mathrm{PhD}^{2}$

Vineet M. Arora, MD, MAPP ${ }^{6}$

Arghavan Salles, $\mathrm{MD}, \mathrm{PhD}^{7}$

${ }^{1}$ University of Miami Miller School of Medicine,

Miami, FL, USA

${ }^{2}$ Department of Public Health Sciences, University of Miami Miller School of Medicine,

Miami, FL, USA

${ }^{3}$ Department of Obstetrics and Gynecology, NYU Grossman School of Medicine,

New York, NY, USA

${ }^{4}$ Mayo Clinic Graduate School of Biomedical Sciences, Rochester, MN, USA

${ }^{5}$ University of Louisville School of Medicine,

Louisville, KY, USA
${ }^{6}$ Department of Medicine, University of Chicago Pritzker School of Medicine,

Chicago, IL, USA

${ }^{7}$ Stanford University Department of Medicine, Clayman Institute for Gender Research, Palo Alto, CA, USA

Corresponding Author: Arghavan Salles, $M D, P h D$; Stanford University Department of Medicine, Clayman Institute for Gender Research, Palo Alto, CA, USA (e-mail: Arghavan@alumni.stanford.edu).

Author Contribution Levy and Salles had full access to all of the data in the study and took responsibility for the integrity of the data and the accuracy of the data analysis. Concept and design: Levy, Kelly, Brown, Arora, and Salles. Acquisition, analysis, or interpretation of data: all authors. Drafting of the manuscript: Levy, Arora, Caban-Martinez, and Salles. Critical revision of the manuscript for important intellectual content: all authors. Statistical analysis: Levy, Kelly, Arora, Caban-Martinez, and Salles. Administrative, technical, or material support: Caban-Martinez, Arora, and Salles. Supervision: Caban-Martinez, Arora, and Salles.

Funding Research reported in this publication was supported by the National Cancer Institute of the National Institutes of Health under Award Number P30CA240139. The content is solely the responsibility of the authors and does not necessarily represent the official views of the National Institutes of Health. (Caban-Martinez)

There was no funder/sponsor role in the design and conduct of the study; collection, management, analysis, and interpretation of the data; preparation, review, or approval of the manuscript; and decision to submit the manuscript for publication.

\section{Declarations:}

Ethics Approval: The study protocol was reviewed and approved by the University of Miami, IRB (\#20210222).

Conflict of Interest: The authors declare that they do not have a conflict of interest.

\section{REFERENCES}

1. Schirmer D, Kawass JF, Adashi EY. Fertility care amidst the COVID19 pandemic: the American experience. J of Ovarian Res. 2021;14:34.

2. Stentz NC, Griffith KA, Perkins E, Jones RD, Jagsi R. Fertility and Childbearing Among American Female Physicians. J Womens Health (Larchmt). 2016 Oct;25(10):1059-1065. doi: https://doi.org/10.1089/ jwh.2015.5638.

3. Nowell LS, Norris JM, White DE, Moules NJ. Thematic Analysis: Striving to Meet the Trustworthiness Criteria. Int J Qual Methods. 2017;16(1):1-13. doi:https://doi.org/10.1177/1609406917733847

4. Goda GS, Streeter JL. The Impact of the Covid-19 Pandemic on the Trajectories of Key Life Milestones. Stanford Cent Longev. 2021:1-10.

5. Marshall AL, Arora VM, Salles A. Physician Fertility: A Call to Action. Acad Med. 2020;95(5):679-681. doi: https://doi.org/10.1097/ACM. 0000000000003079

6. Salles A, Jagsi R. Institutional imperatives for the advancement of women in medicine and science through the COVID-19 pandemic. The Lancet. 2021; 398(10304): 937-939. https://doi.org/10.1016/S0140-6736(21) 01912-7

Publisher's Note Springer Nature remains neutral with regard to jurisdictional claims in published maps and institutional affiliations. 